INPE-13718-PRE/8911

\title{
MULTIPLES FAULTS DETECTION AND ISOLATION IN SENSORS OF DYNAMIC SYSTEMS
}

Adilson de Jesus Teixeira* Marcelo Lopes de Oliveira e Souza Álvaro Prieto Oliva**

* IAE/CTA

** EMBRAER

Trabalho apresentado no Congresso SAE Brasil 2005, realizado de 22 a 24 de novembro de 2005, em São Paulo - SP. 
Publicado por:

esta página é responsabilidade do SID

Instituto Nacional de Pesquisas Espaciais (INPE)

Gabinete do Diretor - (GB)

Serviço de Informação e Documentação (SID)

Caixa Postal 515 - CEP 12.245-970

São José dos Campos - SP - Brasil

Tel.: (012) 3945-6911

Fax: (012) 3945-6919

E-mail: pubtc@sid.inpe.br

Solicita-se intercâmbio We ask for exchange

Publicação Externa - É permitida sua reprodução para interessados. 
INPE-13718-PRE/8911

\section{MULTIPLES FAULTS DETECTION AND ISOLATION IN SENSORS OF DYNAMIC SYSTEMS}

Adilson de Jesus Teixeira

Marcelo Lopes de Oliveira e Souza

Álvaro Prieto Oliva

Trabalho apresentado no Congresso SAE Brasil 2005, realizado de 22 a 24 de novembro de 2005, em São Paulo - SP. 


\title{
Multiples Faults Detection and Isolation in Sensors of Dynamic Systems
}

\author{
Adilson de Jesus Teixeira \\ IAE - Instituto de Aeronáutica e Espaço \\ Marcelo Lopes de Oliveira e Souza \\ INPE - Instituto Nacional de Pesquisas Espaciais \\ Álvaro Prieto Oliva \\ EMBRAER - Empresa Brasileira de Aeronáutica
}

Copyright (C) 2005 Society of Automotive Engineers, Inc

\begin{abstract}
Several papers presents fault detection and isolation techniques for fault in only one sensor; in this paper we will present a technique for multiples faults detection and isolation in sensors of dynamic systems. Multiples faults have less probability to occur but it is not null. So in critical applications the system needs to be operational even in this situation.
\end{abstract}

In this paper we will present a design for a Multiples Faults Detection and Isolation (MFDI) system, an example to illustrate this technique and its respective results.

\section{INTRODUCTION}

In critical applications, the fault in a component can be catastrophic if the control does not have any degree of redundancy, physical or analytical. Therefore, it is important to implement a control system with redundancy and capability to detect and isolate faults in components as fast as possible, such a way, that it can be able to reconfigure the use of the remaining components or even the control law with faults to an alternative control law.

In this paper we will only consider sensor faults. To test a sensor we need to have its respective redundant signal. Redundant signals can be supplied by a redundant sensor, physical redundancy, or by a mathematical procedure, analytical redundancy. Our technique is to be employed in situations where it is not possible to use physical redundancy or to improve a voting system performance.

Multiples Faults Detection and Isolation (MFDI) technique, presented in this paper, makes use of analytical redundancy approach. To do so we will employ observers to generate redundant signals $[1,3-8,13]$. These redundant signals and the real sensor signal will be processed by a decision function to generate fault signatures called residues. These fault signatures will be processed by a logic function which will allow detecting and isolating the faults.

This technique can be applied in any dynamic system that can be represented by a linear time invariant state model. The main steps of this technique are: 1) design the observer for the desired dynamic; 2) design the decision functions to generate the faults signatures; 3) design the logic functions, and 4) evaluate the MFDI system performance in detection and isolation of faulty sensors.

\section{BASIC CONCEPTS}

A fault detection and isolation technique is an algorithm to detect and isolate (locate) faulty components in a dynamic process, such as sensor biases, actuator malfunctions, leaks and equipment deterioration. Fault detection is the first step to achieve fault tolerance, but for this the redundancy has to be included in the system. The redundancy can be either by hardware (physical redundancy) or by software (analytical redundancy). Hardware redundancy, e.g., an extra sensor or extra actuator, can produce several problems associated with: cost, space, weight and complexity of the system. Besides, it has been observed that redundant components tend to have similar functioning expectancies; so the event that causes one component to fail probably could cause its redundant components to fail soon. Analytical redundancy is a mathematical procedure that uses the system mathematical model; therefore this approach only needs some system computational resources to be implemented. 
In this paper we will use the word fault instead of failure because strictly speaking the term failure suggests complete breakdown while fault may connote something tolerable.

FAULT - Fault can be defined as a malfunction of any component of a system, causing since a loss of performance up to a total stop of its functions. According to [1] the faults can be divided in:

- Abrupt Fault: fault that suddenly occurs and persists in a component.

- Incipient Fault: fault that develops slowly at a component.

The early detection of an incipient fault can help to avoid a total breakdown of the system or even catastrophes that could result in loss of significant amount of material or serious personal injury. So, it is desired to have a fault tolerant system, that is, a system that can continue to do its tasks, even when there are hardware faults or software errors. But the implementation of such system is not easy to do.

According to the terminology used in [2], the fault detection and diagnosis consist of the following tasks:

- Fault Detection: detection that something is wrong in the system. Special emphasis is laid upon incipient faults rather than abrupt faults because incipient faults are harder to detect.

- Fault Isolation: determination of the fault origin.

- Fault Identification: determination of the gravity of the fault.

Other relevant aspects, in fault detection and isolation, are the problems relative to false alarm and alarm loss. False Alarm is the indication of the occurrence of a fault when the system is operating at its normal state. Alarm Loss, on the other hand, is the indication that the system is operating normally, when it is at a faulty state. The decision threshold between the fault state and normal state of operation should be chosen in such a way to minimize these wrong and conflicting indications.

REDUNDANCY - A wide class of fault detection and isolation methods makes explicit use of the system mathematical model, such as the model-based methods, which are based on the idea of the analytical redundancy [3]. In contrast with the physical redundancy, where measurements of different sensors are compared, in the analytical redundancy the measurements supplied by a sensor are compared with the respective variable value obtained through a mathematical model. Such value is obtained through calculations that use current and/or previous measurements of another variable and the mathematical model that describes their relationships. The idea can still be extended only for the comparison of the values generated analytically, each of them being obtained through different calculations. In both cases, the resultant differences are called residues.

RESIDUES - The residues have zero value in ideal situations but in practice this rarely happens. The deviations of this value are a combined result of the noise, parameters change and/or faults. If the deviations due noise and parameters are negligible, the residues can be analyzed directly for a decision threshold. If the residue is greater then the decision threshold we can declare that a fault occurred.

For multiple fault detection and isolation approaching the residues must be processed to indicate the fault conditions. Based on definitions given in [4], for multiple fault detection and isolation in sensors we can define: a residue vector $\boldsymbol{r}(t)$ is a vector that its elements have null or very small values, in the faults absence, and they have values different from zero when a fault occurs. This definition implies that a residue vector $\boldsymbol{r}(t)$ has to be independent of or, at least, insensitive to system states, control input and unmeasured disturbances.

In case of linear systems, a general structure of a linear residue generator can be described as in the Figure 1.

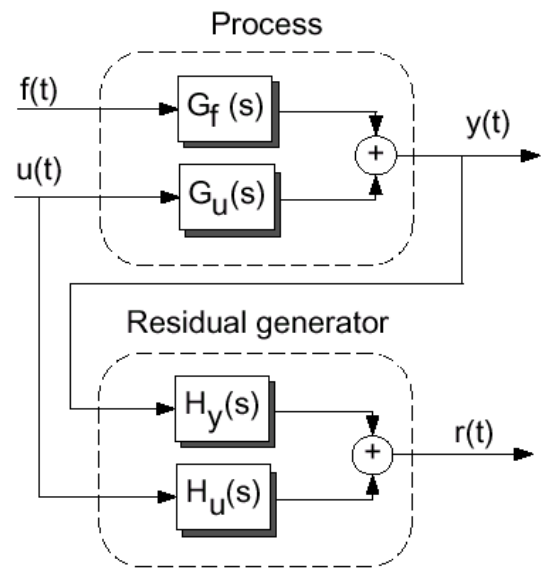

Figure 1 - General structure of a linear residue generator.

The transfer function from the fault $f(t)$ to the residue $r(t)$ is given by:

$$
\boldsymbol{r}(s)=\boldsymbol{H}_{y}(s) \boldsymbol{G}_{f}(s) \boldsymbol{f}(s)
$$

Note: for easy identification, we will use bold italic letters to represent matrix and vectors and regular italic letters for scalar variables.

DETECTABILITY - The condition, for the system to be able to detect a fault is based on the detectability definition [4]. Detectability is the capability to detect a fault at the vector $r(s)$ when its elements have values different from zero. 
However, this condition is not sufficient in some practical situations. Assume that we have two residue generators as presented in the Figure 1. And in fault occurrence the residues behave as in Figure 2. Here we see that we have a fundamentally different behavior between $\boldsymbol{r}_{1}(t)$ and $\boldsymbol{r}_{2}(t)$, because $\boldsymbol{r}_{1}(t)$ only reflects transitions on the faulty signal while $\boldsymbol{r}_{2}(t)$ has approximately the same shape of the faulty signal. Thus, $\boldsymbol{r}_{1}(t)$ can not be used in a reliable MIFD application even though it is clear that $\boldsymbol{r}_{1}(s) \neq 0$.
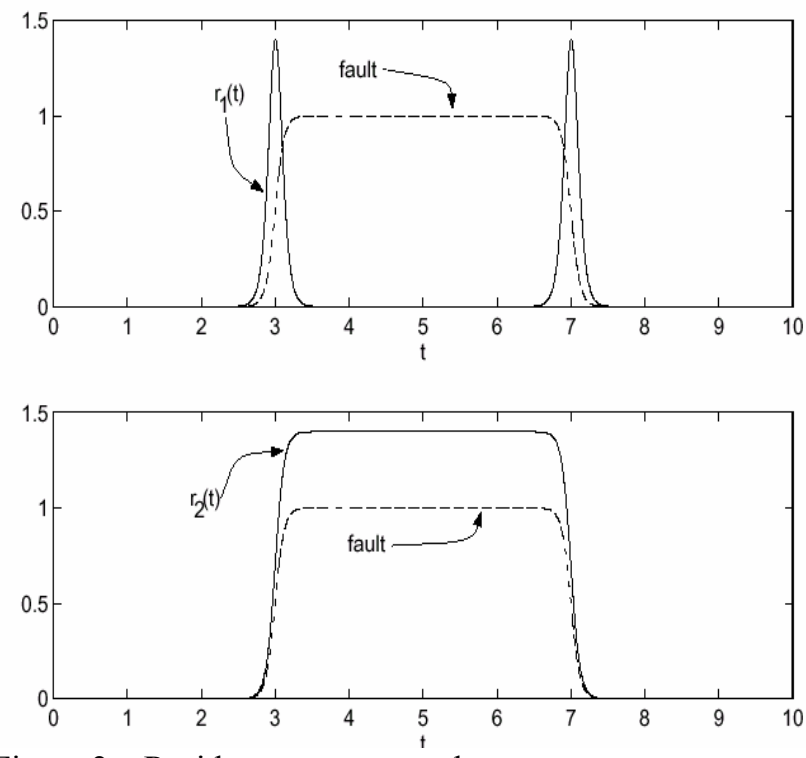

Figure 2 - Residue vector examples.

The difference between these two residues in this example is the values of $r(s=0)$. Clearly we can see that the residue 1 has $\boldsymbol{r}_{1}(s=0)=\boldsymbol{0}$ while the residual 2 has $\boldsymbol{r}_{2}(s=0) \neq \boldsymbol{0}$. This leads to the definition of strong detectability. The fault is said to have strong detectability if and only if:

$$
\boldsymbol{r}_{i}(s=0) \neq 0
$$

\section{DETECTION AND ISOLATION STRATEGIES}

To design residues strongly detectable, we can base on the structured residue methods described in [1] to develop the residues vector generator.

\section{ANALITYCAL REDUNDANT SIGNALS} GENERATOR - The conception of the Analytical Redundant Signals Generator (ARSG) can be based on a bank of Reduced Order Observers (ROO) similar to the Dedicated Observer Scheme (DOS), described in [1]. As in DOS structure, only the system control signal of and one of the measures are used as input signal for each ROO. The $i \frac{i^{t h}}{}$ ROO is, therefore, sensitive only to the $i^{\underline{t h}}$ sensor fault. An ARSG block diagram for $p$ sensors is presented in Figure 3.

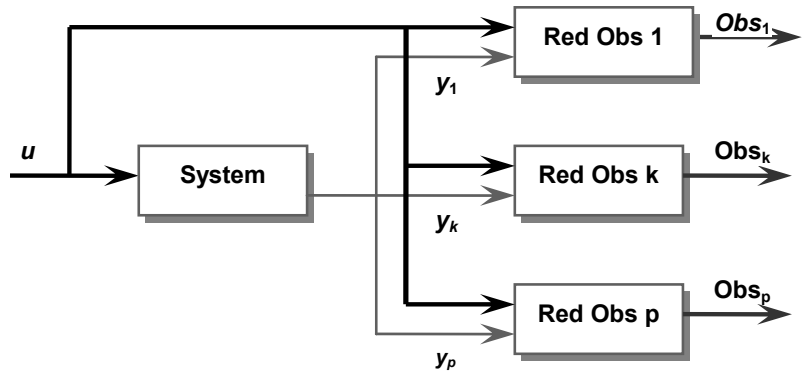

Figure 3 - Analytical Redundant Signal Generator.

DECISION FUNCTIONS - The decision functions are used to generate the fault signatures, i. e., they process the residue vectors. For this MFDI technique, the decision functions are developed considering the module of the error between the sensor output and the equivalent values obtained by the ROO output.

The dimension of these residues vectors are $(p-1)$ where $\mathrm{p}$ is the number of sensors.

To easy determine the decision threshold, the sensor signals output and respective estimated signals are submitted to a scale factor conversion, such a way that all signals output will operate at the same range. Range from -10 uni to +10uni is a good choice.

So the elements of the $i^{t h}$ decision function vector are formed by:

$$
\eta_{j, i}=\left|y_{i}-O b s_{i, j}\right| S_{i} \Rightarrow\left\{\begin{array}{l}
i=1, \ldots, p \\
j=1, \ldots, p ; j \neq i
\end{array}\right.
$$

where $p$ is the number of sensors, $y_{i}$ is the output of the $i^{\text {th }}$ sensor, $\boldsymbol{O b s}_{i, j}$, the $i^{\text {th }}$ element of $\boldsymbol{O b s}_{j}$, is the estimated value of $y_{i}$ supplied by $j^{\text {th }}$ ROO and $S_{i}$ is the scale factor to be applied to the module of the error, to do the normalization of the measures supplied by sensors.

At Figure 4 we show two cases of what happens to decision function for sensor $i$ when there is an intermittent fault at sensor $i$ and at sensor $j$. First occurs an intermittent fault at sensor $j, j \neq i$, during a fault at sensor $i$ and after occurs an intermittent fault only at sensor $j$. Remain sensors are kept at normal state.

When sensor $i$ fault begins, 10s, all elements its decision function changes from small values to the sensor $i$ fault amplitude value. At $15 \mathrm{~s}$ occurs a fault at sensor $j$. As $\mathrm{ROO} j$ is no more driven by a correct sensor information, its estimated values does not reflect correct measures. Besides, after sensor $j$ transition from normal state to the fault state, the ROO $j$ converges asymptotically to this new state. Generally it produces pulses in all residues calculated from estimated values supplied by ROOj. During this fault at 
sensor $j$ the residue $r_{i, j}$ contains incorrect sensor $i$ fault amplitude. At 30s finishes sensor $i$ fault and at 35s begins again sensor $j$ fault. Now there is only a fault at sensor $j$. As ROO $j$ does not reflect the real state of sensor $i$, it shows a value different from zero. If a FDI system uses only the $r_{i, j}$ residue to detect and isolate the fault for sensor $i$, at first sensor $j$ fault it could declare an alarm loss and at second sensor $j$ fault it will declare a false alarm. Due this behavior, for a MFDI system, an alarm is only raised when all residues from the same sensor have values above the decision threshold value.

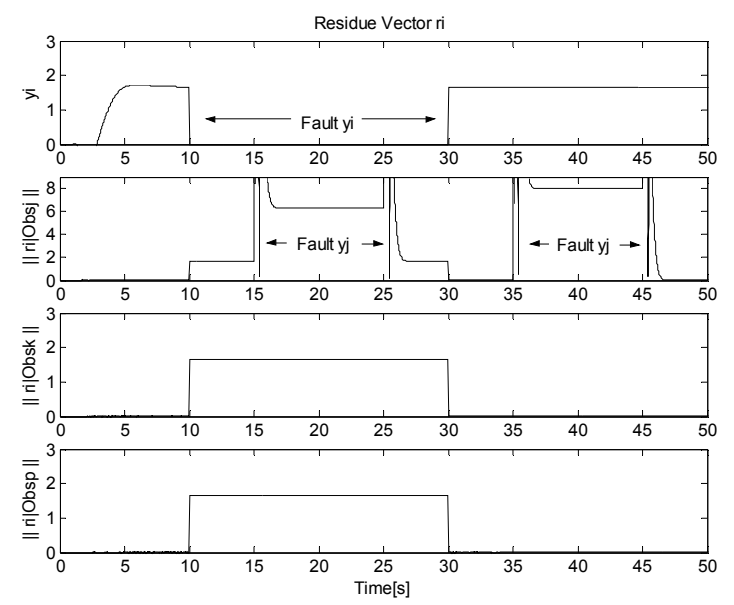

Figure 4 - Decision function for fault in sensors $i$ and $j$.

Relative to alarm loss problem, during $\mathrm{ROO}_{\mathrm{j}}$ stabilization time, the residue vector element $r_{i, j}$ value can cross the level zero, causing sensor $i$ alarm loss. At Figure 5 we show an expansion of the influence of this transition at the decision function element $\eta_{i, j}$ signal.

To get round to this problem all residues vectors module were limited to $1.0 \%$ and the threshold were chosen as $0.5 \%$ of the normalized signal maximum range. After that all signals rate decrease were limited to $0.4 \mathrm{uni} / \mathrm{s}$, such a way to keep all residues module above the decision threshold when occur a multiple fault. By this way we can prevent the alarm loss and there will be no delay to declare the beginning of an abrupt fault. The signal rate decrease only causes a delay for the MFDI system to declare the fault end. Simulations show that this false alarm does not produce a great impact at the control performance, when the system is modeled properly. The delay can be easily determined. For instance, for the range suggested, the time for the signal decrease from 0.10 uni to 0.05 uni with the decrease rate of $0.4 \mathrm{uni} / \mathrm{s}$ is of $0.125 \mathrm{~s}$, so the MFDI system will present a maximum delay of $0.125 \mathrm{~s}$.

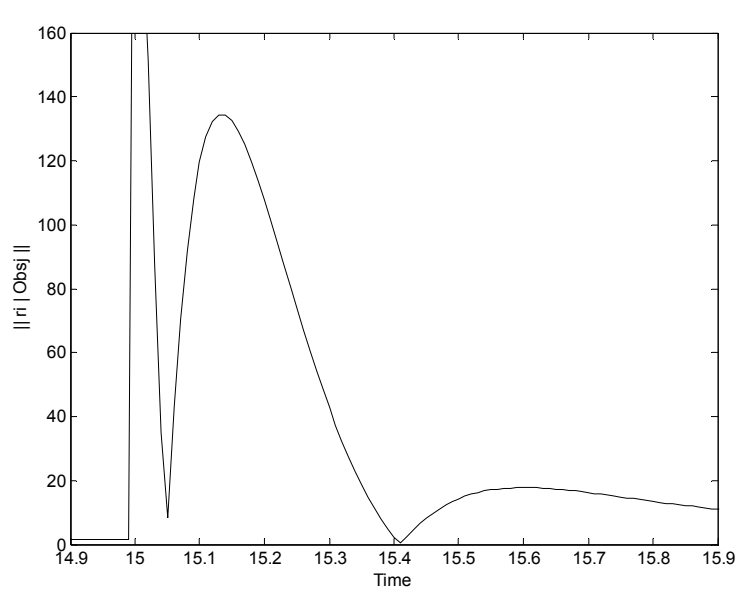

Figure 5 - Influence of $\mathrm{ROO}_{\mathrm{j}}$ stabilization at decision function element $\eta_{i, j}$ signal.

DECISION LOGIC - The decision logic is developed to test the decision functions against predefined decision thresholds. These thresholds must minimize the false alarm and alarm loss.

In this MFDI technique a fault is declared when all elements of a decision function have a value above its respective decision threshold. So this MFDI system can detect up to $p$ - 2 simultaneous fault.

As all decision function are converted by a scale factor, so all decisions threshold value at can be chosen at the same level. We adopted the value $0.5 \%$ of the maximum range of the measure be used as the decision threshold by the decision logic.

ADDITIONAL CONSIDERATIONS - A general system employing an MFDI system can be illustrated as in Figure 6. Once the fault was detected and isolated, the control law can be reconfigured, i. e., the fault signal can be changed for another redundant signal. In case where there are more than one redundant signal, it should be selected that one that presents better information quality for the desired signal.

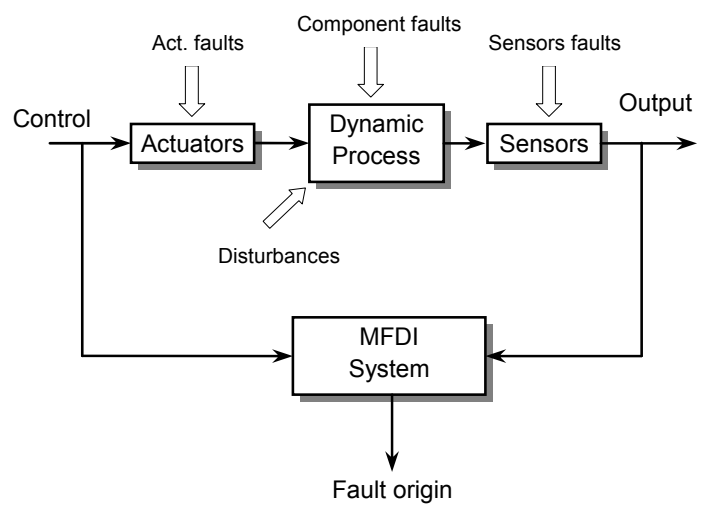

Figure 6 - Structure of a detection and isolation system. 


\section{MODEL BASED STRUCTURE}

In this paper, a model of a linear system, with time invariant parameters, represented in continuous time state space is given by:

$$
\begin{aligned}
& \dot{x}(t)=\boldsymbol{A} \boldsymbol{x}(t)+\boldsymbol{B} u(t) \\
& \boldsymbol{y}(t)=C \boldsymbol{x}(t)+D u(t)
\end{aligned}
$$

where $\boldsymbol{A}$ is a $n \times \mathrm{x} n$ system dynamic matrix; $\boldsymbol{B}$ is a $n \times r$ control matrix; $\boldsymbol{C}$ is a $p \times n$ output matrix; $\boldsymbol{D}$ is a $p \times r$ direct feedthrough matrix, in our case $\boldsymbol{D}=\boldsymbol{0} ; \boldsymbol{x}(t)$ is a $n \times 1$ state vector; $\boldsymbol{u}(t)$ is a $r \times 1$ control vector, and $\boldsymbol{y}(t)$ is a $p \times 1$ output vector.

Note: - the time designation $t$ will be suppressed for easy represent the mathematics development of the equations;

We can consider three types of general of faults to this model:

- Sensor Fault: modeled here as an additive fault of the plant output signal;

- Actuator Fault: modeled as an additive fault of the input signal in the system dynamics, and

- Component Fault: modeled as a additive fault, i. e., any distribution matrix that is added to the system dynamics matrix.

We used the following fault cases for studies [5-8]:

- Zero Value: the sensor, actuator or component begins to supply only the zero value, that is, there is an abrupt variation to the value zero;

- Maximum Value: the sensor, actuator or component begins to supply only the maximum value in module, that is, the sensor has an abrupt variation to its maximum or minimum value;

- Constant Value: the sensor begins to supply the last measurement made before the fault occurs;

There are also uncertainties about the model and disturbances (unmeasured inputs) in the process. If these uncertainties and disturbances are structured, that is, if it is known how they enter in the system dynamic; this information can be incorporated into the model.

Adding the structured uncertainties and disturbances to them model with, eq. (4), the complete model, based on [4], can be represented by:

$$
\begin{aligned}
& \dot{x}=A x+B\left[u+f_{a}\right]+M f_{c}+N d \\
& y=C x+D u+f_{s}
\end{aligned}
$$

where $\boldsymbol{f}_{a}$ denotes actuator faults vector, $\boldsymbol{f}_{c}(t)$ is for component faults vector, $\boldsymbol{f}_{s}$ is for sensor faults vector, $\boldsymbol{d}(t)$ is for disturbances vector acting upon the system, $\boldsymbol{M}$ is the distribution matrix for components fault and $\boldsymbol{N}$ is the distribution matrix for disturbances acting upon the system.

REDUCED ORDER OBSERVERS - For a system model represented by eq. (4) a procedure to get the estimated output vector $\hat{y}$ from the measure of the $i^{t h}$ sensor, $y_{i}$, can be done by observers. As the measure $y_{i}$ is supplied, so there is no need for the observer to estimate this measure again, we can get it direct from $y_{i}$. By this way we can reduce the order of the observer. Reduced order observers can be developed based on the Luenberger Observers [911]. Considering that the observed is controlled by sensor 1 , this estimated value can be represented by:

$$
\hat{\boldsymbol{x}}_{1}=\boldsymbol{x}_{1}=\boldsymbol{C}_{1}^{-1} y_{1}
$$

Following this principle, the model can be partitioned in:

$$
\begin{gathered}
\dot{x}_{1}=A_{11} x_{1}+A_{12} x_{2}+B_{1} u \\
\dot{x}_{2}=A_{21} x_{1}+A_{22} x_{2}+B_{2} u \\
y_{1}=C_{1} x_{1} \\
y_{2}=C_{2} x_{2}
\end{gathered}
$$

A suitable general structure for the estimation of $\boldsymbol{x}_{2}$ [12] can be given by:

$$
\hat{\boldsymbol{x}}_{2}=\boldsymbol{L} y_{1}+\boldsymbol{z}
$$

where $z$ is a state vector of $(p-1)^{t h}$-order system given by:

$$
\dot{\boldsymbol{z}}=\boldsymbol{F} \boldsymbol{z}+\boldsymbol{G} y_{1}+\boldsymbol{H u}
$$

The Luenberger reduced order observer block diagram is presented in Figure 7:

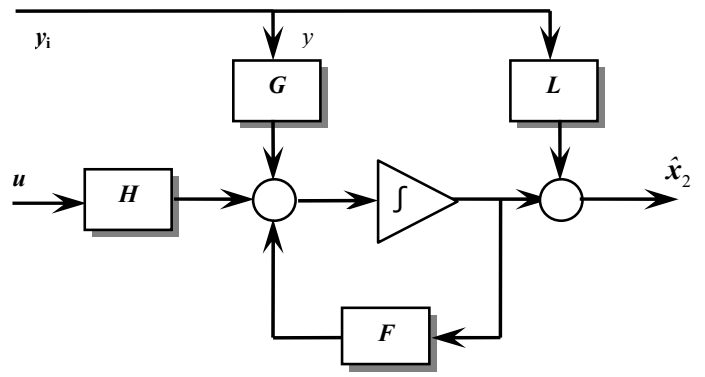

Figure 7-Luenberger reduced order observer block diagram.

The estimated error is given by: 


$$
e=x-\hat{x}=\left[\begin{array}{c}
x_{1}-\hat{x}_{1} \\
x_{2}-\hat{x}_{2}
\end{array}\right]=\left[\begin{array}{l}
e_{1} \\
e_{2}
\end{array}\right]
$$

By eq. (6) we have:

$$
e_{1}=x_{1}-\hat{x}_{1}=0
$$

So we are concerned only with $\boldsymbol{e}_{2}$, which must be calculated to be null. It can be done through its differential equation:

$$
\begin{gathered}
\dot{\boldsymbol{e}}_{2}=\dot{\boldsymbol{x}}_{2}-\dot{\hat{\boldsymbol{x}}}_{2}=A_{21} \boldsymbol{x}_{1}+\boldsymbol{A}_{22} \boldsymbol{x}_{2}+\boldsymbol{B}_{2} \boldsymbol{u}-\boldsymbol{L} \dot{y}-\dot{\boldsymbol{z}} \\
\dot{\boldsymbol{e}}_{2}=\boldsymbol{A}_{21} \boldsymbol{x}_{1}+\boldsymbol{A}_{22} \boldsymbol{x}_{2}+\boldsymbol{B}_{2} \boldsymbol{u}-\boldsymbol{L}\left[\boldsymbol{C}_{1}\left(\boldsymbol{A}_{11} \boldsymbol{x}_{1}+\boldsymbol{A}_{12} \boldsymbol{x}_{2}+\boldsymbol{B}_{1} \boldsymbol{u}\right)\right] \\
-\boldsymbol{F} \boldsymbol{z}-\boldsymbol{G} y_{1}-\boldsymbol{H u}
\end{gathered}
$$

From eq. (9) we have:

$$
\boldsymbol{z}=\hat{\boldsymbol{x}}_{2}-\boldsymbol{L} y_{1}=\boldsymbol{x}_{2}-\boldsymbol{e}_{2}-\boldsymbol{L} y_{1}=\boldsymbol{x}_{2}-\boldsymbol{e}_{2}-\boldsymbol{L} \boldsymbol{C}_{1} \boldsymbol{x}_{1}
$$

Applying eq. (14) in eq. (13) we get:

$$
\begin{aligned}
\dot{\boldsymbol{e}}_{2}= & \boldsymbol{F e _ { 2 }}+\left(\boldsymbol{A}_{21}-\boldsymbol{L} \boldsymbol{C}_{1} \boldsymbol{A}_{11}-\boldsymbol{G} \boldsymbol{C}_{1}+\boldsymbol{F L} \boldsymbol{C}_{1}\right) \boldsymbol{x}_{1} \\
& +\left(\boldsymbol{A}_{22}-\boldsymbol{L} \boldsymbol{C}_{1} \boldsymbol{A}_{12}-\boldsymbol{F}\right) \boldsymbol{x}_{2}+\left(\boldsymbol{B}_{2}-\boldsymbol{L} \boldsymbol{C}_{1} \boldsymbol{B}_{1}-\boldsymbol{H}\right) \boldsymbol{u}
\end{aligned}
$$

To the error be independent of $\boldsymbol{x}_{1}, \boldsymbol{x}_{2}$ and $\boldsymbol{u}$, the matrices that multiply $\boldsymbol{x}_{1}, \boldsymbol{x}_{2}$ and $\boldsymbol{u}$ must vanish. By this consideration we must have:

$$
\begin{aligned}
& \boldsymbol{F}=\boldsymbol{A}_{22}-\boldsymbol{L} \boldsymbol{C}_{1} \boldsymbol{A}_{12} \\
& \boldsymbol{H}=\boldsymbol{B}_{2}-\boldsymbol{L} \boldsymbol{C}_{1} \boldsymbol{B}_{1} \\
& \boldsymbol{G} \boldsymbol{C}_{1}=\boldsymbol{A}_{21}-\boldsymbol{L} \boldsymbol{C}_{1} \boldsymbol{A}_{11}+\boldsymbol{F} \boldsymbol{L} \boldsymbol{C}_{1}
\end{aligned}
$$

Then eq. (15) becomes:

$$
\dot{\boldsymbol{e}}_{2}=\boldsymbol{F} \boldsymbol{e}_{2}
$$

and hence, for asymptotic stability, the eigenvalues of $\boldsymbol{F}$ must lie in the left half of the $s$ plane.

The reduced order observer is driven only by one sensor information, so the gain matrix $\boldsymbol{L}$ become a vector and it is unique for the desired eigenvalues and so is the matrix $\boldsymbol{F}$. So we need to find a vector $\boldsymbol{L}$ and matrix $\boldsymbol{F}$ to satisfy eq. (16) for the desired eigenvalues. To solve eq. (16) we can use the Bass-Gura formula, converted to observer design, to get the observer gain vector [12]:

$$
\boldsymbol{L}=\left[(\boldsymbol{O W})^{T}\right]^{-1}(\boldsymbol{f}-\boldsymbol{a})
$$

$$
\boldsymbol{O}=\left[\left(\boldsymbol{C}_{1} A_{12}\right)^{\boldsymbol{T}}, \boldsymbol{A}^{T}\left(\boldsymbol{C}_{1} A_{12}\right)^{T}, \ldots,\left(\boldsymbol{A}^{T}\right)^{k-1}\left(\boldsymbol{C}_{1} A_{12}\right)^{T}\right]
$$

is the observability test matrix,

$$
\boldsymbol{f}=\left[\begin{array}{c}
f_{1} \\
\vdots \\
f_{k}
\end{array}\right]
$$

is a vector with the desired characteristic equation coefficients: $s^{k}+f_{l} s^{k-1}+\ldots+f_{\mathrm{k}}=0$,

$$
\boldsymbol{a}=\left[\begin{array}{c}
a_{1} \\
\vdots \\
a_{k}
\end{array}\right]
$$

is a vector with $\boldsymbol{A}_{22}$ characteristic equation coefficients: $s^{k}+a_{1} s^{k-1}+\ldots+a_{\mathrm{k}}=0$, and

$$
\boldsymbol{W}=\left[\begin{array}{cccc}
1 & a_{1} & \cdots & a_{k-1} \\
0 & 1 & \cdots & a_{k-2} \\
\vdots & \vdots & \ddots & \vdots \\
0 & 0 & \cdots & 1
\end{array}\right]
$$

is the Toeplitz triangular matrix.

The residue vector is then given by:

$$
\begin{aligned}
& r_{1}=y_{1}-\hat{y}_{1}=C_{1}\left(x_{1}-\hat{x}_{1}\right)=0 \\
& r_{2}=y_{2}-\hat{y}_{2}=C_{2}\left(x_{2}-\hat{x}_{2}\right)=C_{2} e
\end{aligned}
$$

Using the same procedure above we can design all $p$ ROOs for the MFDI system.

FAULT INFLUENCE - The fault influence in the observer can be used to detect and isolate the fault. In this paper we are concerned only with sensor faults, so the terms: $\boldsymbol{f}_{a}, \boldsymbol{f}_{c}$, and $\boldsymbol{d}$ are considered null, then eq. (8) becomes:

$$
\begin{aligned}
& \boldsymbol{y}_{1}=\boldsymbol{C}_{1} \boldsymbol{x}_{1}+f_{s} \\
& \boldsymbol{y}_{2}=\boldsymbol{C}_{2} \boldsymbol{x}_{2}
\end{aligned}
$$

Using the same procedure as before to get the error, we have:

$$
\begin{aligned}
\dot{\boldsymbol{e}}_{2}= & \boldsymbol{F} \boldsymbol{e}_{2}+\left(\boldsymbol{A}_{21}-\boldsymbol{L} \boldsymbol{C}_{1} \boldsymbol{A}_{11}-\boldsymbol{G} \boldsymbol{C}_{1}+\boldsymbol{F L} \boldsymbol{C}_{1}\right) \boldsymbol{x}_{1} \\
& +\left(\boldsymbol{A}_{22}-\boldsymbol{L} \boldsymbol{C}_{1} \boldsymbol{A}_{12}-\boldsymbol{F}\right) \boldsymbol{x}_{2}+\left(\boldsymbol{B}_{2}-\boldsymbol{L} \boldsymbol{C}_{1} \boldsymbol{B}_{1}-\boldsymbol{H}\right) \boldsymbol{u} \\
& -\boldsymbol{L} \dot{f}_{s}+(\boldsymbol{F L}-\boldsymbol{G}) f_{s}
\end{aligned}
$$

Applying eqs. (16), (17) and (18) we get:

where: 


$$
\dot{\boldsymbol{e}}_{2}=\boldsymbol{F} \boldsymbol{e}_{2}-\boldsymbol{L} \dot{f}_{s}+(\boldsymbol{F} \boldsymbol{L}-\boldsymbol{G}) f_{s}
$$

So, the error and residue in frequency domain is represented by:

$$
\begin{aligned}
& \boldsymbol{E}_{2}(s)=-\left(\boldsymbol{L}+\boldsymbol{\varphi}_{F} \boldsymbol{G}\right) f_{s}(s) \\
& \boldsymbol{R}_{2}(s)=-\boldsymbol{C}_{2}\left(\boldsymbol{L}+\boldsymbol{\varphi}_{F} \boldsymbol{G}\right) f_{s}(s)
\end{aligned}
$$

where $\boldsymbol{\varphi}_{F}=(s-\boldsymbol{F})^{-1}$

Note that the residue will converge to a plane formed by the vectors $\boldsymbol{L}$ and $\boldsymbol{\varphi}_{F} \boldsymbol{G}$ if $\boldsymbol{G}$ is an eingenvector of $\varphi_{F}$. Similar result can also be gotten through the Modified Detection Filter for Sensor Faults [13].

\section{EXAMPLE}

We used the example presented in $[13,14]$, with some changes, to illustrate this methodology. The original example is of order 3 , as this methodology can detect and isolate up to $p-2$ multiples faults, we increased the system order, adding the state $\dot{x}_{4}(t)=1.0 x_{1}(t)-1.0 x_{3}(t)$ and the element $A(1,4)=1$ to keep the observability matrices, eq (21), with full rank for all ROOs. We also added element $B_{4}=1$ to the $\boldsymbol{B}$ vector to keep the system controllable. It was adopted the output matrix $\boldsymbol{C}=\boldsymbol{I}_{4}$, due the restriction of the reduced order methodology supplied by eq. (6). So the system model is represented by the following matrices and vectors:

$$
\boldsymbol{A}=\left[\begin{array}{cccc}
0 & 3 & 4 & 1 \\
1 & 2 & 3 & 0 \\
0 & 2 & 5 & 0 \\
1 & 0 & 0 & -1
\end{array}\right], \boldsymbol{B}=\left[\begin{array}{c}
-3 \\
1 \\
0 \\
1
\end{array}\right], \boldsymbol{C}=\boldsymbol{I}_{4}, \boldsymbol{D}=\boldsymbol{0}
$$

The pair $(\boldsymbol{A}, \boldsymbol{B})$ is completely controllable and the pair $(\boldsymbol{A}, \boldsymbol{C})$ is completely observable. The eigenvalues and eigenvectors of $\boldsymbol{A}$ are:

$$
\begin{gathered}
\Lambda=\{6.70062,1.31370,-1.82787,-0.186450\} \\
V_{A}=\left[\begin{array}{rrrr}
0.602986 & -0.614589 & 0.622103 & 0.527448 \\
0.514277 & -0.652878 & -0.210945 & -0.512290 \\
0.604811 & 0.354219 & 0.061789 & 0.197549 \\
0.0783035 & -0.265630 & -0.751447 & 0.648330
\end{array}\right]
\end{gathered}
$$

As we can see the system is unstable. At Figure 8 there is the plant response to a unitary step input beginning at $1 \mathrm{~s}$.

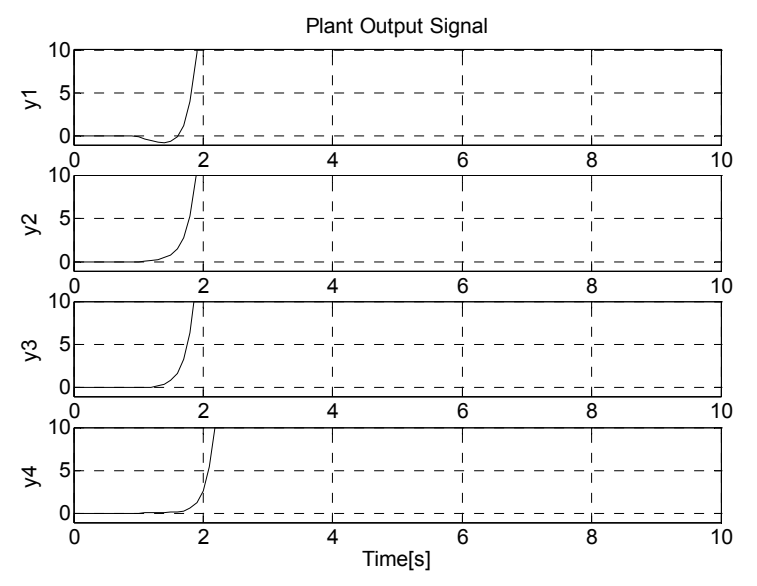

Figure 8 - Plant response to a step input.

CONTROL SYSTEM - Control system is not part of a MFDI system design. How the plant is unstable we had to design a control system to stabilize it. As the plant is completely controllable and all state variables can be measured, we used a pole place methodology for a type 1 servo system using a type 0 plant employing the Ackermann's formula [15]. After several tests we chose the following close-loop poles which permit to get an overshoot less then $4 \%$ and a stabilization time less then $4 \mathrm{~s}$ for a step input:

$$
\boldsymbol{\Lambda}_{\mathrm{d}}=\{-1.25,-1.50,-1.75,-2.00,-2.25\}
$$

The block diagram of the controlled plant is showed at Figure 9, the controller gains calculated are showed at Table 1, and at Figure 10 we have the controlled plant response to the same step input used before.

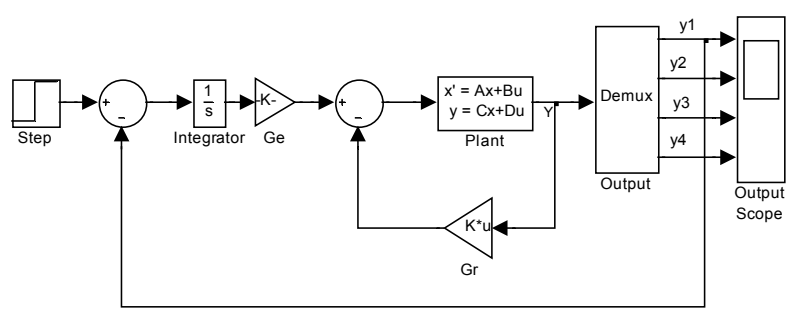

Figure 9 - Block diagram with the control system.

Table 1 - Controller gains.

\begin{tabular}{|c|c|}
\hline Gain & Value \\
\hline & 9.60815 \\
& 41.1739 \\
$\mathrm{Gr}$ & 67.6015 \\
& 2.40057 \\
\hline $\mathrm{Ge}$ & -0.984375 \\
\hline
\end{tabular}

Note: all the values were calculated using Matlab double precision but they are showed with 6 digits approximation. 


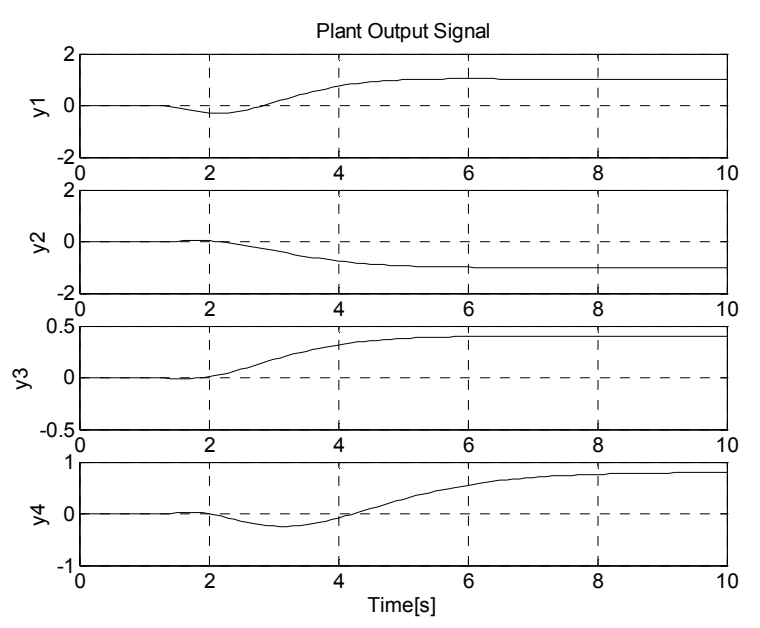

Figure 10 - Controlled plant response to a step input.

To evaluate the MFDI system the controlled plant was submitted to the input signal showed at Figure 11. The plant output signal for each sensor is showed at Figure 12.

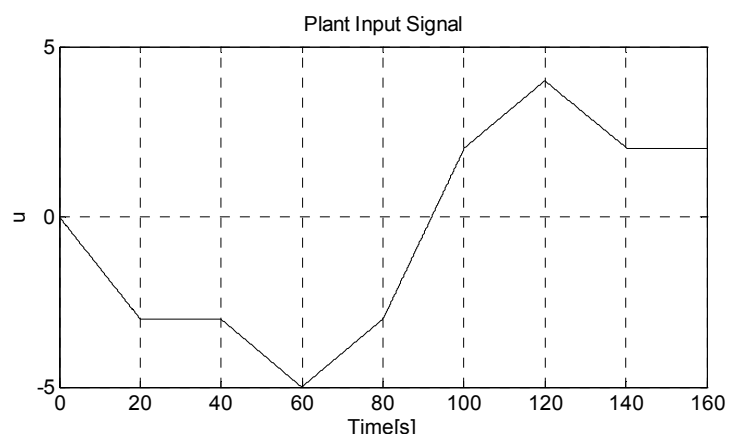

Figure 11 - Input signal applied to the system.

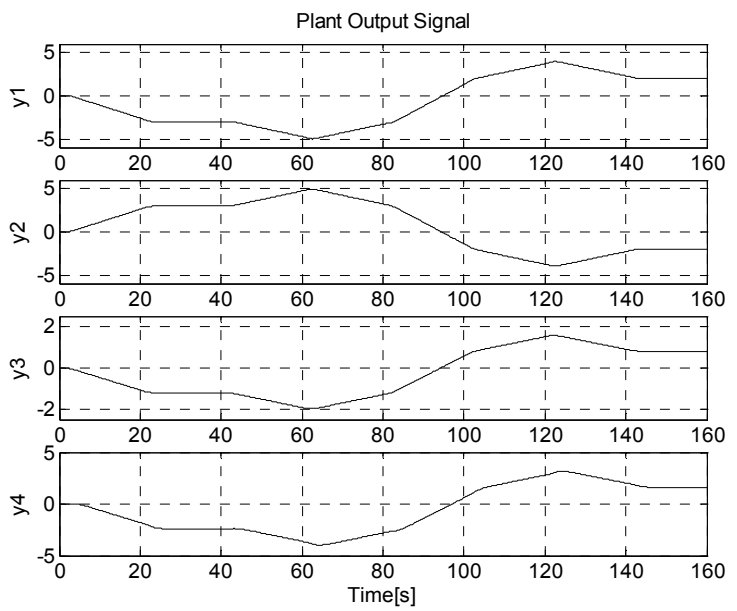

Figure 12 - Plant output signal.

REDUCED ORDER OBSERVERS DESIGN - The reduced order observers for each sensor were calculated using the following poles:

$$
\boldsymbol{\Lambda}_{O}=\left[\begin{array}{lll}
-7.0 & -7.5 & -8.0
\end{array}\right]
$$

Applying the Bass-Gura methodology to design the reduced order observer we got the following matrices and vectors gains presented at Table 2 .

Table 2 - Observers matrices and vectors gains.

\begin{tabular}{|c|c|c|c|c|}
\hline Desc. & Param. & Values & & \\
\hline \multirow{4}{*}{ Obs 1} & $L 1$ & $\begin{array}{c}-8.77419 \\
10.5806 \\
3.50000\end{array}$ & & \\
\hline & $F 1$ & $\begin{array}{r}28.3226 \\
-29.7419 \\
-10.5000\end{array}$ & $\begin{array}{r}38.0968 \\
-37.3226 \\
-14.0000\end{array}$ & $\begin{array}{c}8.77419 \\
-10.5806 \\
-4.50000\end{array}$ \\
\hline & $G 1$ & $\begin{array}{c}186.290 \\
-170.968 \\
-70.7500\end{array}$ & & \\
\hline & $\boldsymbol{H} 1$ & $\begin{array}{l}-25.3226 \\
31.7419 \\
11.5 \\
\end{array}$ & & \\
\hline \multirow{4}{*}{ Obs 2} & $\boldsymbol{L} 2$ & $\begin{array}{r}-5.60811 \\
7.70270 \\
-9.85135\end{array}$ & & \\
\hline & $F 2$ & $\begin{array}{c}5.60811 \\
-7.70270 \\
10.8514\end{array}$ & $\begin{array}{r}20.8243 \\
-18.1081 \\
29.5541 \\
\end{array}$ & $\begin{array}{r}1.00000 \\
0.00000 \\
-1.00000 \\
\end{array}$ \\
\hline & $G 2$ & $\begin{array}{r}133.318 \\
-109.689 \\
196.345\end{array}$ & & \\
\hline & $\boldsymbol{H} 2$ & $\begin{array}{c}2.60811 \\
-7.70270 \\
10.8514\end{array}$ & & \\
\hline \multirow{4}{*}{ Obs 3} & $L 3$ & $\begin{array}{c}7.25000 \\
26.0000 \\
26.7500\end{array}$ & & \\
\hline & $F 3$ & $\begin{array}{l}-12.5000 \\
-49.0000 \\
-53.5000 \\
\end{array}$ & $\begin{array}{l}1.00000 \\
0.00000 \\
1.00000\end{array}$ & $\begin{array}{r}0.00000 \\
1.00000 \\
-1.00000 \\
\end{array}$ \\
\hline & $G 3$ & $\begin{array}{l}-97.8750 \\
-454.500 \\
-522.375\end{array}$ & & \\
\hline & H3 & $\begin{array}{c}1.00000 \\
-3.00000 \\
1.00000 \\
\end{array}$ & & \\
\hline \multirow{4}{*}{ Obs 4} & $L 4$ & $\begin{array}{c}6.41935 \\
45.9355 \\
20.5000\end{array}$ & & \\
\hline & $F 4$ & $\begin{array}{l}2.00000 \\
2.00000 \\
3.00000 \\
\end{array}$ & $\begin{array}{l}3.00000 \\
5.00000 \\
4.00000\end{array}$ & $\begin{array}{l}-5.41935 \\
-45.9355 \\
-20.5000 \\
\end{array}$ \\
\hline & G4 & $\begin{array}{c}45.9677 \\
-653.226 \\
-195.750\end{array}$ & & \\
\hline & H4 & $\begin{array}{l}-5.41935 \\
-45.9355 \\
-23.5000\end{array}$ & & \\
\hline
\end{tabular}


At Figure 13 we have the residue vector between the measure supplied for the sensor 1 and the values estimated by the observers 2, 3 and 4 . Note that the residues are low proving that the observers designed have a good performance in estimating the sensor 1 signals. The same performances were also gotten in estimating other sensors signals.
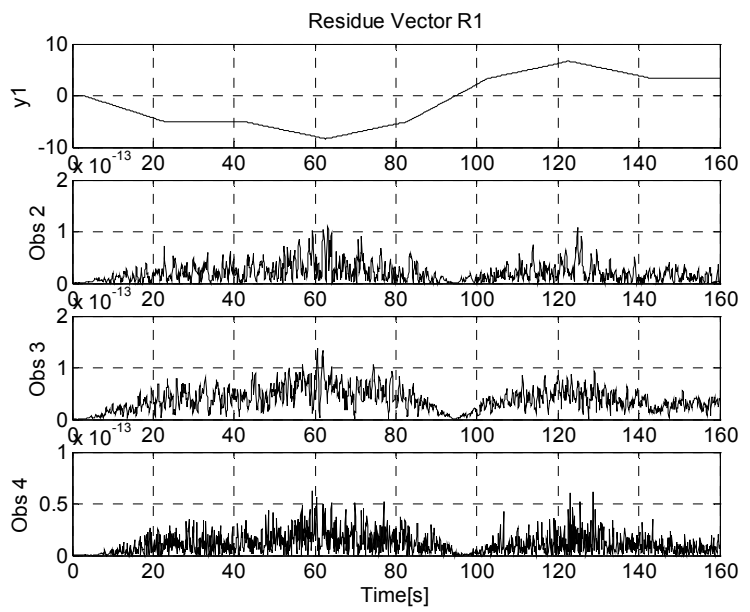

Figure 13-Residue vector for the sensor 1 estimated signals.

SCALE FACTOR - The scale factors were calculated using approximately the maximum range module of each signal added of $20 \%$. These ranges are converted to a normalized range from -10uni to 10uni. So evaluating all the signals in the same range becomes easier to define the threshold values. At Table 3 we have approximately the maximum magnitude module for each sensor output signal, related to the input signal showed at Figure 11, and the scale factor to convert these signals to the range specified above.

Table 3-Maximum output signal range module and respective scale factor.

\begin{tabular}{|c|c|c|}
\hline Output & $\begin{array}{c}\text { Module } \\
\text { Max. Value }\end{array}$ & Scale Factor \\
\hline$y_{1}$ & 5 & $10 / 6.0$ \\
\hline$y_{2}$ & 5 & $10 / 6.0$ \\
\hline$y_{3}$ & 2 & $10 / 2.5$ \\
\hline$y_{4}$ & 4 & $10 / 5.0$ \\
\hline
\end{tabular}

FAULT CASE - To show the MFDI performance we simulated intermittent faults at the sensors. The fault types and activation time intervals are showed at Table 4. At Figure 14 we have the respective faults time diagram. We can see simple and double intermittent faults. The simulation was done in the Simulink - Dynamic System Simulation for Matlab environment, version 5.0 (release 13), using fixed step integration of $0.01 \mathrm{~s}$ and ode5 - Dormand-Prince solver.
Table 4 - Fault types and activation time intervals.

\begin{tabular}{|c|c|c|}
\hline Sensor & Fault Type & Fault Intervals \\
\hline 1 & Constant Value & $5 \mathrm{~s}$ to $50 \mathrm{~s}$ \\
\hline 2 & Maximum Value & $\begin{array}{c}10 \mathrm{~s} \text { to } 15 \mathrm{~s} \\
60 \mathrm{~s} \text { to } 90 \mathrm{~s}\end{array}$ \\
\hline \multirow{2}{*}{3} & \multirow{3}{*}{ Zero Value } & $25 \mathrm{~s}$ to $30 \mathrm{~s}$ \\
& & $65 \mathrm{~s}$ to $70 \mathrm{~s}$ \\
& & $400 \mathrm{~s}$ to $115 \mathrm{~s}$ \\
\hline & \multirow{3}{*}{$4045 \mathrm{~s}$} \\
& Minimum Value & $80 \mathrm{~s}$ to $85 \mathrm{~s}$ \\
& & $105 \mathrm{~s}$ to $110 \mathrm{~s}$ \\
& & $125 \mathrm{~s}$ to $130 \mathrm{~s}$ \\
\hline
\end{tabular}
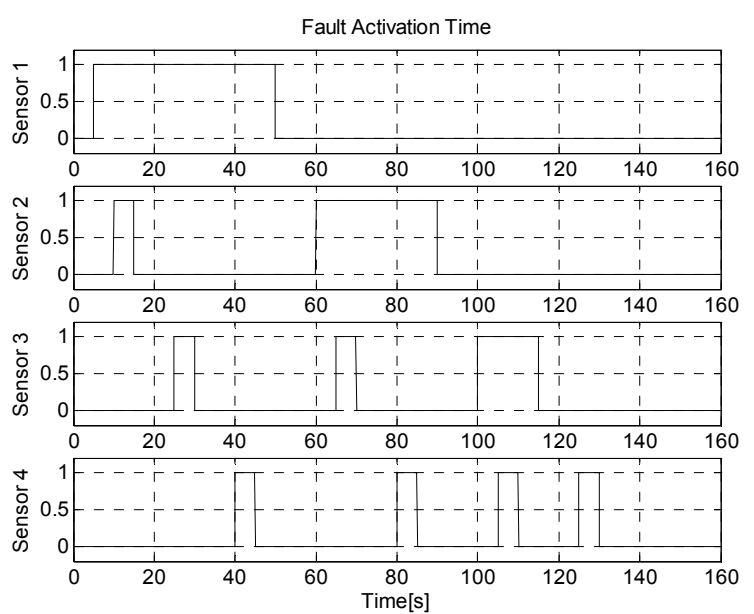

Figure 14 - Faults time diagram for the sensors.

At Figure 15 we have the sensor output signals in faults presence. The signals generated by sensor 1 decision function are showed at Figure 16. As mentioned before, when one observer is driven by faulty information the estimated values does not reflect the real measure, so it can indicate a false alarm or an alarm loss.
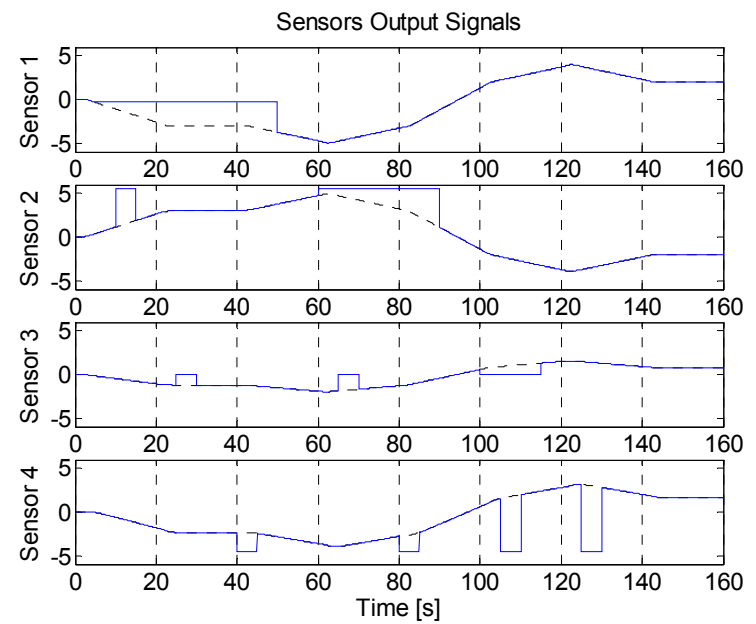

Figure 15 - Sensors output signals in faults presence. 


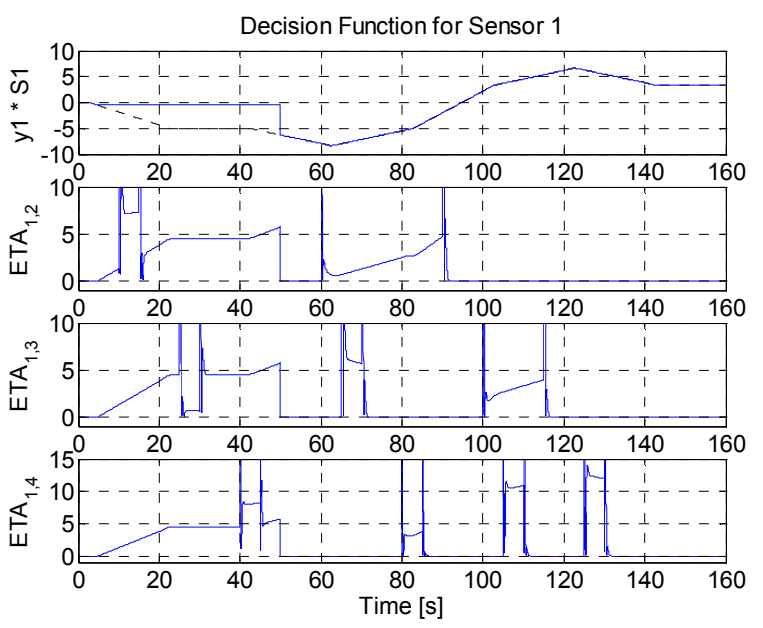

Figure 16-Signals generated by decision function for residue $\mathrm{R} 1$.

DECISION THRESHOLD - The decision threshold value must be chosen such a way to minimize the false alarm and the alarm loss. So its value must be chosen between the maximum residue value, when there is no fault, to the maximum acceptable measure error value. For this MFDI technique, when there are multiples faults, it is necessary to define the amplitude signal limiters, the decision threshold to avoid false alarm and the rate decrease signal limiters to avoid alarm loss, for each residue module after the application of the scale factor.

In the present example it was chosen that the maximum acceptable error value for the sensor measure is 0.05 uni. Checking the residue signals for alarm loss we chose the signal limiter to 0.1 uni and a signal decrease limiter to $0.4 \mathrm{uni} / \mathrm{s}$. Using these nonlinearities we got a conditioned signal showed at Figure 17 which permits to reduce the alarm loss.
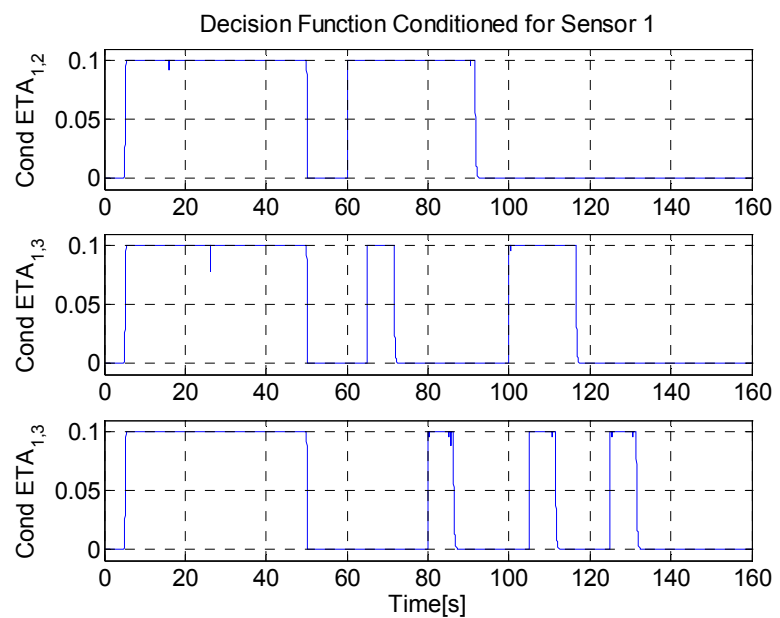

Figure 17 - Conditioned signal generated by decision function for sensor 1 .

This methodology only declares a fault when all conditioned signal is above the decision threshold value
0.05. Its is easy to see at Figure 17 that this situation, for sensor 1, only occurred approximately during the time interval from $5 \mathrm{~s}$ to $50 \mathrm{~s}$. A more precise measure at the simulations results we got the time interval of $5.04 \mathrm{~s}$ to $50.12 \mathrm{~s}$. It must be remembered that this sensor was subject to a constant fault, what contributed for the delay in the beginning of the detection.

The same considerations were applied to the others residues. By this way the MFDI can detect multiple sensor faults. At Figure 18 we have the faults isolated by the system and at Table 5 we have the respective fault detection and isolation time intervals.
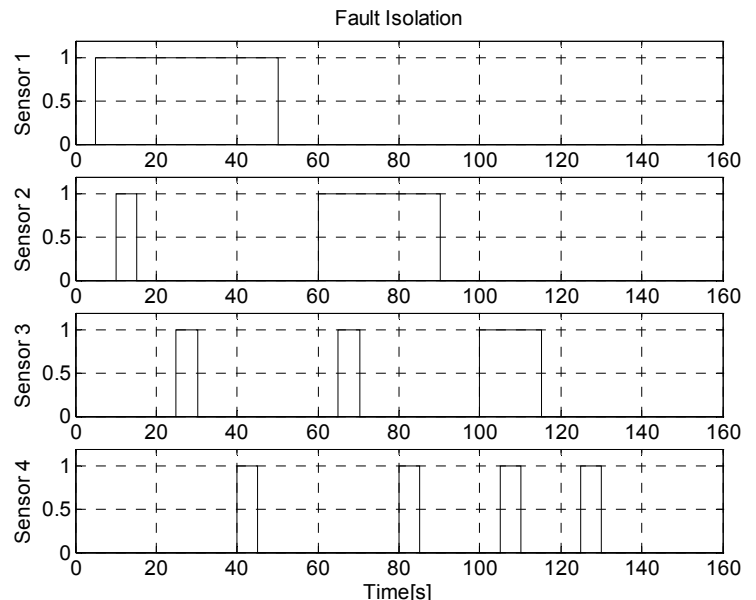

Figure 18 - Fault detection and isolation for multiple faults.

Table 5 - Fault detection and isolation time intervals.

\begin{tabular}{|c|c|c|c|}
\hline Sensor & Fault Type & $\begin{array}{c}\text { Fault } \\
\text { Intervals }\end{array}$ & $\begin{array}{c}\text { FDI Time } \\
\text { Intervals }\end{array}$ \\
\hline 1 & $\begin{array}{c}\text { Constant } \\
\text { Value }\end{array}$ & $5 \mathrm{~s}$ to $50 \mathrm{~s}$ & $5.04 \mathrm{~s}$ to $50.12 \mathrm{~s}$ \\
\hline 2 & Maximum & $10 \mathrm{~s}$ to $15 \mathrm{~s}$ & $10 \mathrm{~s}$ to $15.12 \mathrm{~s}$ \\
& Value & $60 \mathrm{~s}$ to $90 \mathrm{~s}$ & $60 \mathrm{~s}$ to $90.12 \mathrm{~s}$ \\
\hline \multirow{3}{*}{3} & Zero Value & $25 \mathrm{~s}$ to $30 \mathrm{~s}$ & $25 \mathrm{~s}$ to $30.12 \mathrm{~s}$ \\
& & $65 \mathrm{~s}$ to $70 \mathrm{~s}$ & $65 \mathrm{~s}$ to $70.12 \mathrm{~s}$ \\
& & $400 \mathrm{~s}$ to $115 \mathrm{~s}$ & $100 \mathrm{~s}$ to $115.12 \mathrm{~s}$ \\
\hline \multirow{3}{*}{4} & Minimum & $80 \mathrm{~s}$ to $85 \mathrm{~s}$ & $40 \mathrm{~s}$ to $45.12 \mathrm{~s}$ \\
& Value & $105 \mathrm{~s}$ to 110 & $105 \mathrm{~s}$ to $110.12 \mathrm{~s}$ \\
& & $125 \mathrm{~s}$ to $130 \mathrm{~s}$ & $125 \mathrm{~s}$ to $130.12 \mathrm{~s}$ \\
\hline
\end{tabular}

\section{CONCLUSIONS AND COMMENTS}

The MFDI methodology presented allows detecting up to $p$-2 multiple sensors fault. The decision threshold is easy to choose for simple fault. Unfortunately, it is not so easy to choose when there is more than one fault because the observer that is driven by a faulty sensor does not estimate correct values which can cause an alarm loss or false alarm. 
Limiting the signal above to the decision threshold and applying a decrease signal limiter rate for the signal is a way to filter the signal in order to reduce alarm loss and false alarm rate without reducing the detection of the fault beginning.

The conversion of the signals in the same range makes it easier to see the estimated signal behavior when the respective observer is driven by fault information.

A new challenge will be to develop a MFDI system that allows detecting up to $p$ multiple sensor faults.

\section{BIBLIOGRAPHICAL REFERENCES}

[ 1] - Patton, R.; Frank, P. and Clark, R., "Fault Diagnosis in Dynamics Systems: Theory and Applications". Prentice Hall Int. Series in Systems and Control Engineering, Englewood Cliffs, NJ, 1989.

[2] - Gertler, Janos J., "Survey of Model-Based Failure Detection and Isolation in Complex Plants". IEEE Control Systems Magazine, Vol. 8, nº 6, pp. 3-11, December 1988.

[3] - Chow, E. Y. and Willsky, A. S., "Analytical Redundancy and the Design of Robust Failure Detection Systems". IEEE Trans. Automatic Control, Vol. AC-29, $\mathrm{n}^{\mathrm{o}}$ 7, pp. 603-614, July 1984.

[ 4] - Frisk, E., "Model-based Fault Diagnosis Applied to a SI-Engine”. site www.vehicular.isy.liu.if, Linköping University, Linköping, Sweden, 1996.

[ 5] - Teixeira, A. J., Souza, M. L. O. and Oliva, A. P., "Eigenstructure Techniques for Fault Detection and Isolation in Aerospace and Automotive Systems". SAE BRASIL 2004 Congress, site www.saebrasil.org.br, nov 2004.

[6] - Teixeira, A. J., Souza, M. L. O. and Oliva, A. P., "Techniques For Fault Diagnosis In Aerospace And Automotive Systems". SAE BRASIL 2003 Congress, site www.saebrasil.org.br, nov 2003.

[ 7] - Teixeira, A. J., Souza, M. L. O. and Oliva, A. P., “An Algorithm for Instrument Fault Detection in Inertial Sensors of a Satellite Launcher Vehicle Control System". COBEM 2003 Congress, 2003.

[8] - Oliva, Álvaro P., "Sensor Fault Detection and Analytical Redundancy Satellite Launcher Flight Control System”. SBA Controle \& Automação, Vol. 9, nº. 3, pp. 156-164, 1998.

[ 9] - Luenberger, David G., "Observer for Multivariable Systems". IEEE Trans. Automatic Control, Vol. AC-11, n⿳o 2, pp. 100-197, April 1966.

[10] - Luenberger, David G., "An Introduction to Observers". IEEE Trans. Automatic Control, Vol. AC-16, no 6, pp. 596-602, December 1971.

[11] - Chen, C. T., "Introduction to Linear Systems Theory". Holt, Rinehart and Winston Co., New York, 1984.
[12] - Friedland, Bernard, "Control System Design - An Introduction to State-Space Methods”. McGraw-Hill Book Company, 1986.

[13] - Mello, A. F. e Souza M. L. O., “A Modified Detection Filter for Sensor Faults". AAS/AIAA Space Flight Mechanics Meeting, Huntsville, Al., USA, 10-12, Paper AAS97-196, February 1997.

[14] - White, John E., Speyer, Jason L., "Detection Filter Design: Spectral Theory and Algorithms". IEEE Trans. Automatic Control, Vol. AC-32, no 7, pp. 593-603, July 1987.

[15] - Ogata, Katsuhiko, "Engenharia de Controle Moderno”. Pearson - Prentice Hall, 2003.

ABOUT THE AUTHOR - Adilson de Jesus Teixeira received the Electronics Engineer degree in 1981 from the University of Parahyba Valley, at S. José dos Campos, São Paulo, Brazil; and his Master of Science degree in Electronics Engineering in 1989 from the Aeronautics Technological Institute in the same city; he is a doctoral candidate in Space Engineering and Technology Course of the National Institute for Space Research-INPE, at the same city; and he is a Development Engineer at the Institute of Aeronautics and Space-IAE of the Aerospace Technological Center-CTA in the same city for more than twenty years.

Email: adilson@iae.cta.br 


\section{PUBLICAÇÕES TÉCNICO-CIENTÍFICAS EDITADAS PELO INPE}

Teses e Dissertações (TDI)

Teses e Dissertações apresentadas nos Cursos de Pós-Graduação do INPE.

\begin{abstract}
Notas Técnico-Científicas (NTC)
Incluem resultados preliminares de pesquisa, descrição de equipamentos, descrição e ou documentação de programa de computador, descrição de sistemas e experimentos, apresentação de testes, dados, atlas, e documentação de projetos de engenharia.
\end{abstract}

Propostas e Relatórios de Projetos (PRP)

São propostas de projetos técnicocientíficos e relatórios de acompanhamento de projetos, atividades e convênios.

\section{Publicações Seriadas}

São os seriados técnico-científicos: boletins, periódicos, anuários e anais de eventos (simpósios e congressos). Constam destas publicações o Internacional Standard Serial Number (ISSN), que é um código único e definitivo para identificação de títulos de seriados.

Pré-publicações (PRE)

Todos os artigos publicados em periódicos, anais e como capítulos de livros.
Manuais Técnicos (MAN)

São publicações de caráter técnico que incluem normas, procedimentos, instruções e orientações.

Relatórios de Pesquisa (RPQ)

Reportam resultados ou progressos de pesquisas tanto de natureza técnica quanto científica, cujo nível seja compatível com o de uma publicação em periódico nacional ou internacional.

Publicações Didáticas (PUD)

Incluem apostilas, notas de aula e manuais didáticos.

\section{Programas de Computador (PDC)}

São a seqüência de instruções ou códigos, expressos em uma linguagem de programação compilada ou interpretada, a ser executada por um computador para alcançar um determinado objetivo. São aceitos tanto programas fonte quanto executáveis. 